\title{
Cr(VI) Femoval from Ground Waters by Ferrous Iron Redox-Assisted Coagulation in a Continuous Treatment Unit Comprising a Plug Flow Pipe Reactor and Downflow Sand Filtration
}

\author{
Ioannis A. Katsoyiannis *, Maria Xanthopoulou and Anastasios I. Zouboulis \\ Laboratory of Chemical and Environmental Techmology, Department of Chemistry, Aristotle University of \\ Thessaloniki, 54124 Thessaloniki, Greece; mariaxanth@chem.auth.gr (M.X.); zoubouli@chem.auth.gr (A.I.Z.) \\ * Correspondence: katsogia@chem.auth.gr
}

Received: 26 December 2019; Accepted: 21 January 2020; Published: 23 January 2020

Featured Application: The present study shows the application of a water treatment unit based on pipe flocculation and sand filtration for applications at the household level, with minimum maintenance requirements in order to remove chromium(VI) to concentrations lower than $10 \mu \mathrm{g} / \mathrm{L}$, which might be the future $\mathrm{Cr}(\mathrm{VI})$ drinking water limit.

\begin{abstract}
Chromium(VI) $(\mathrm{Cr}(\mathrm{VI}))$ is the main chromium species found in groundwater and is considered as a highly toxic and carcinogenic element to humans. In the present study, removal of $\mathrm{Cr}(\mathrm{VI})$ by coagulation with ferrous iron is studied in a continuous flow treatment unit comprising pipe flocculation reactors followed by a sand filter. The studied parameters, regarding their effect on the removal of hexavalent chromium, were the ferrous iron dose, the effect of linear velocity, and the effect of the starting $\mathrm{Cr}(\mathrm{VI})$ concentration. The experiments have shown that the $\mathrm{Cr}(\mathrm{VI})$ removal achieved was very efficient and residual $\mathrm{Cr}(\mathrm{VI})$ and total $\mathrm{Cr}$ concentration in the treated water was lower than $10 \mu \mathrm{g} / \mathrm{L}$, provided that the required dose of ferrous iron is provided. In particular, the study demonstrated that the removal of hexavalent chromium, from initial concentration of $50 \mu \mathrm{g} / \mathrm{L}$ and $100 \mu \mathrm{g} / \mathrm{L}$, was more than $90 \%$ with ferrous doses of $1 \mathrm{mg} / \mathrm{L}$ and $2 \mathrm{mg} / \mathrm{L}$ respectively, applying linear velocity of $8 \mathrm{~m} / \mathrm{h}$, at an initial $\mathrm{pH}$ value of 7.3. Iron concentration in treated water was very low, far below $200 \mu \mathrm{g} / \mathrm{L}$, which is the limit for iron in drinking water. This unit comprises a simple treatment option, for applications at the household level, with minimum maintenance requirements capable of removing $\mathrm{Cr}(\mathrm{VI})$ to concentrations below $10 \mu \mathrm{g} / \mathrm{L}$, which might be the future limit for chromium in drinking water.
\end{abstract}

Keywords: hexavalent chromium; pipe flocculation; sand filtration; continuous operation; ferrous sulphate

\section{Introduction}

The presence of chromium in natural and engineered aquatic systems is due to natural sources as well as to anthropogenic activities. Natural sources of chromium are mainly rock disintegration $[1,2]$, whereas anthropogenic activities that contribute to elevated chromium concentrations in water sources are mainly industrial activities, such as for example the electroplating industry, stainless steel production, leather tanning, and textile manufacturing [3]. In water, chromium is present in its two most stable oxidation states, namely, $\mathrm{Cr}(\mathrm{III})$, and $\mathrm{Cr}(\mathrm{VI})$. In chromium-containing natural water, the prevailing form is $\mathrm{Cr}(\mathrm{VI})$, because it is very soluble, whereas $\mathrm{Cr}(\mathrm{III})$ is quite insoluble, easily forming complexes with iron oxides or other minerals and, therefore, precipitating out of water [4]. 
Several studies have reported increased concentrations of chromium in natural waters, especially in groundwaters across the world such as in the USA, Mexico, India, Canada, and Italy as well as in Greece [1,5,6]. For example, Kaprara et al. (2015) [1] investigated the occurrence of $\mathrm{Cr}(\mathrm{VI})$ in drinking waters in Greece. In approximately 600 samples taken throughout Greece, and focusing on areas with geological substrate predominated by ultramafic minerals, it was found that about $20 \%$ of samples contained $\mathrm{Cr}(\mathrm{VI})$ concentration of more than $10 \mu \mathrm{g} / \mathrm{L}, 14 \%$ of the samples had $\mathrm{Cr}(\mathrm{VI})$ concentrations of $10-30 \mu \mathrm{g} / \mathrm{L}$ and $6 \% 30-50 \mu \mathrm{g} / \mathrm{L}$. Concentrations exceeding the limit of $50 \mu \mathrm{g} / \mathrm{L}$ were found in only $3 \%$ of the samples. In most of the cases, $\mathrm{Cr}(\mathrm{VI})$ presence was of natural origin of $\mathrm{Cr}(\mathrm{VI})$ in groundwater. In addition, it was found that in all cases, $\mathrm{Cr}(\mathrm{VI})$ was the species accounting for more than $95 \%$ of the total concentration of chromium.

Concerning the effect of chromium species on human health, $\mathrm{Cr}(\mathrm{III})$ is relatively non-toxic, and is an essential trace element for the human body [7]. In contrast, water-soluble hexavalent chromium compounds are particularly irritating, corrosive and toxic to the tissues of the human body. Furthermore, $\mathrm{Cr}(\mathrm{VI})$ is considered a human carcinogen [8,9]. It is for these reasons that $\mathrm{Cr}(\mathrm{VI})$ is classified as a priority pollutant as by the World Health Organization (WHO), the European Commission and the United States Environmental Protection Agency (US-EPA). To date, the maximum concentration limit for total chromium in water, for the European Commission and the U.S. EPA, is $50 \mu \mathrm{g} / \mathrm{L}$ and $100 \mu \mathrm{g} / \mathrm{L}$, respectively. However, in July 2014, the state of California first set a limit for the Cr (VI) concentration at $10 \mu \mathrm{g} / \mathrm{L}$. This is at the moment withdrawn [10], but the debate has started also within European countries of setting a limit for $\mathrm{Cr}(\mathrm{VI})$ at the lower ppb level. The WHO report recommends maintaining the current parametric value of $50 \mu \mathrm{g} / \mathrm{L}$ for total chromium, however it remarks that the value for chromium remains under review, suggesting the introduction of a lower value for chromium, and in particular for the more toxic $\mathrm{Cr}(\mathrm{VI})$. The European Commission is considering, therefore, proposing to reduce the value by $50 \%$ to $25 \mu \mathrm{g} / \mathrm{L}$ and offer a transition period of 10 years after the entry into force of the new Directive for water quality intended for human consumption. Therefore, in this study the primary aim is firstly to examine the removal of $\mathrm{Cr}(\mathrm{VI})$ by ferrous iron by this innovative treatment unit and secondly to examine the conditions under which residual concentrations of $\mathrm{Cr}(\mathrm{VI})$ below 25 and $10 \mu \mathrm{g} / \mathrm{L}$ can be achieved [11].

Many methods, such as physicochemical adsorption [12], bioremediation [13], chemical reduction [14-16], membrane separation [17] and ion exchange [18] have been developed to enable remediation of $\mathrm{Cr}(\mathrm{VI})$ contamination from waters. Among them, the most widely used treatment method applied to industrial wastewaters or groundwaters containing hexavalent chromium is its chemical reduction and precipitation by using it as reducing agent, such as ferrous iron [14]. In this technology hexavalent chromium is reduced to its trivalent form and then precipitates, mainly in the form of hydroxide $\left[\mathrm{Cr}(\mathrm{OH})_{3}\right](\log \mathrm{Ksp}=-32.3)$ or complexes with iron oxides $[4,15,19]$. The method is based on following reactions:

$$
\begin{gathered}
\mathrm{H}_{\mathrm{x}} \mathrm{CrO}_{4}{ }^{\mathrm{x}-2}(\mathrm{aq})+3 \mathrm{Fe}^{2+}(\mathrm{aq})+\mathrm{jH}_{2} \mathrm{O} \rightarrow \mathrm{Cr}(\mathrm{OH})_{\mathrm{y}}{ }^{3-y}(\mathrm{aq})+3 \mathrm{Fe}(\mathrm{OH})_{\mathrm{z}}{ }^{3-\mathrm{z}}(\mathrm{aq})+\mathrm{jH}^{+} \\
\mathrm{xCr}(\mathrm{III})+(1-\mathrm{x}) \mathrm{Fe}(\mathrm{III})+3 \mathrm{H}_{2} \mathrm{O} \rightarrow\left(\mathrm{Cr}_{\mathrm{x}} \mathrm{Fe}_{1-\mathrm{x}}\right)(\mathrm{OH})_{3}(\mathrm{~s})+3 \mathrm{H}^{+}
\end{gathered}
$$

$\mathrm{Fe}$ (II) reacts with $\mathrm{Cr}$ (VI) and promotes its reduction to $\mathrm{Cr}$ (III), while Fe (II) is oxidized to Fe (III), creating insoluble ferric hydroxide particles $\left[\mathrm{Fe}(\mathrm{OH})_{3}\right]$. $\mathrm{Cr}$ (III) is precipitated either as hydroxide or as mixed oxides of $\mathrm{Cr}$ (III)-Fe(III) [20]. The resulting precipitates can be separated from the water by conventional sand or membrane filtration [20].

The main objective of this research is to study the removal of hexavalent chromium from water by chemical reduction and precipitation using ferrous sulfate as the reducing agent followed by sand filtration, using an innovative treatment apparatus, which runs in full-scale mode and uses pipe reactors to promote the reaction of $\mathrm{Fe}(\mathrm{II})$ with $\mathrm{Cr}(\mathrm{VI})$

To the best of our knowledge, until to date, this is the first time, that hexavalent chromium removal is investigated using a continuous treatment unit, based in pipe flocculation reactors followed by sand 
filtration. In addition, a further aim of this study was to propose a treatment plant, which will be simple in use, with low capital and operational costs, but very efficient in the removal of hexavalent chromium, in order to contribute to the fulfillment of the sustainable goal 6, which is aiming at providing clean water for all [21].

\section{Materials and Methods}

\subsection{Simulated Groundwater}

The water used to conduct the experimental part of this study was drinking water from the city of Thessaloniki, Greece, having the typical composition of groundwater, because its major part comes from groundwater wells around the city. The water was firstly filtered through an activated carbon filter, in order to remove the residual chlorine and then spiked with $\mathrm{Cr}(\mathrm{VI})$. Afterwards, it was used for investigating the removal of $\mathrm{Cr}(\mathrm{VI})$ by ferrous iron. The major chemical parameters of $\mathrm{Cr}(\mathrm{VI})$-contaminated water are given in Table 1.

Table 1. Physicochemical parameters of the drinking water from the city of Thessaloniki [19].

\begin{tabular}{cc}
\hline Parameter & Average Value \\
\hline $\mathrm{pH}$ & 7.3 \\
Conductivity $(\mu \mathrm{s} / \mathrm{cm})$ & 560 \\
Total Hardness $(\mathrm{mg} \mathrm{CaCO} / \mathrm{L})$ & 290 \\
Iron $(\mu \mathrm{g} / \mathrm{L})$ & $<20$ \\
Manganese $(\mu \mathrm{g} / \mathrm{L})$ & $<5$ \\
Sulfate $(\mathrm{mg} / \mathrm{L})$ & 12 \\
Total Organic Carbon $(\mathrm{TOC})(\mathrm{mg} / \mathrm{L})$ & 0.25 \\
Nitrate $(\mathrm{mg} / \mathrm{L})$ & 2 \\
Chloride $(\mathrm{mg} / \mathrm{L})$ & 15 \\
Total Chromium $(\mu \mathrm{g} / \mathrm{L})$ & $<1$ \\
\hline
\end{tabular}

\subsection{Chemicals}

$\mathrm{Cr}(\mathrm{VI})$ stock solutions were prepared by dissolving a certain amount of $\mathrm{K}_{2} \mathrm{Cr}_{2} \mathrm{O}_{7}$ (pro analysis, Merck, Darmstadt, Germany) in de-ionized water, of conductivity less than $2 \mu \mathrm{S} / \mathrm{cm}$. Afterwards, in the simulated groundwater, proper volume of stock solution was diluted in about $200 \mathrm{~L}$ of water to prepare the storage tank of groundwater, which was ready to be treated by the proposed technology. Ferrous iron working solutions were freshly prepared every day by dissolving $\mathrm{FeSO}_{4} \cdot 7 \mathrm{H}_{2} \mathrm{O}$ (pro analysis, Merck, Darmstadt, Germany) in free chlorine drinking water and stored in a $10 \mathrm{~L}$ tank. The reagent was acidified with concentrated hydrochloric acid 32\% (pro analysis, Merck, Darmstadt, Germany) to a final $\mathrm{pH}$ value of about 3 , in order to slow down ferrous iron oxidation from atmospheric oxygen, because $\mathrm{Fe}(\mathrm{II})$ oxidation by oxygen is very slow at acidic $\mathrm{pH}$ values [22].

\subsection{Experimental Setup}

The design of the experimental set up is shown in Figure 1 and the caption contains all essential information for its operation. 


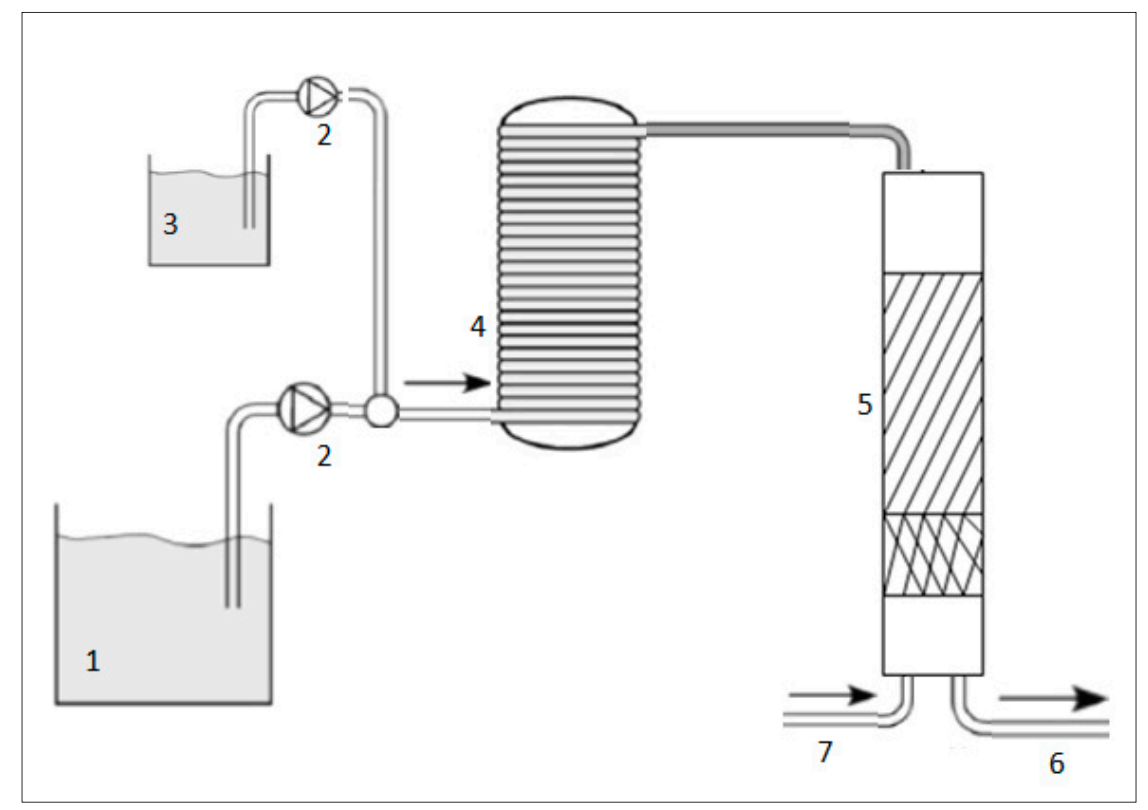

Figure 1. Schematic presentation of chromium (VI) removal process. (1: Influent: Chromium (VI) spiked drinking water, 2: peristaltic pump, 3: Reductant addition unit, 4: Pipe reactor system, 5: Bi-layered sand filter, 6: Effluent, 7: Backwashing inlet. Column height: $1 \mathrm{~m}$, Sand bed height: $50 \mathrm{~cm}$, Inner diameter: $68 \mathrm{~mm}$ ).

This comprised two treatment parts in row. In the first part, chromium reduction took place in a reactor consisting of pipes via the addition of ferrous sulfate, and in the second part, the produced precipitates were removed by sand filtration. The characteristics of the treatment plant are given in the figure caption.

The chromium-polluted water was prepared in the 200-L tank. A peristaltic pump drove the polluted water into the pipe reactor system and the flow rate was adjusted accordingly at 15, 30, 44 and $54 \mathrm{~L} / \mathrm{h}$. A peristaltic pump pushed the reductant (ferrous sulphate) into the pipe reactor system. The flow rate of peristaltic pump was set at $2 \mathrm{~L} / \mathrm{h}$. In the pipe reactor system, the polluted water was mixed with the reductant and the red-ox reaction took place. $\mathrm{Fe}(\mathrm{II})$ was oxidized to $\mathrm{Fe}(\mathrm{III})$ and $\mathrm{Cr}(\mathrm{VI})$ was reduced to $\mathrm{Cr}(\mathrm{III})$. The experimental runs took place at the $\mathrm{pH}$ value of the tap water of Thessaloniki which is $7.3 \pm 0.1$. The water flowed afterwards through the sand filter, and the formed particles which contain iron and the reduced hexavalent chromium were removed from the water stream by filtration.

Sampling locations included: (a) the inlet water tank, representing the feedwater influent, corresponding to water spiked with $\mathrm{Cr}(\mathrm{VI})$ and (b) the filtered effluent. Total chromium, $\mathrm{Cr}(\mathrm{VI})$, Total Iron and $\mathrm{Fe}(\mathrm{II}), \mathrm{pH}$ of treated water and conductivity were measured in each sample on an hourly basis. Regularly, dissolved oxygen and redox potential were measured in these samples.

The experiments were conducted in a continuous operation mode, applying a once through pass of the $\mathrm{Cr}(\mathrm{VI})$ contaminated water through the experimental unit under room temperature $\left(20-22^{\circ} \mathrm{C}\right)$. The studied treatment unit has the capacity of treating 500 to $1200 \mathrm{~L}$ of contaminated groundwater per day, therefore it is simulating treatment needs at the household level, given that the daily water needs per person in Europe is about 130 to $150 \mathrm{~L} /$ day.

\subsection{Determination Methods}

The determination of hexavalent chromium concentrations was performed by the photometric method based on the reaction of $\mathrm{Cr}(\mathrm{VI})$ with diphenylcarbazide (DPC) [23]. In brief, $10 \mathrm{~mL}$ of the sample were placed in a falcon tube and afterwards $200 \mu \mathrm{L}$ of DPC reagent were added. Finally, $100 \mu \mathrm{L}$ of $\mathrm{H}_{2} \mathrm{SO}_{4}$ were added to acidify the sample. The samples were left for $15 \mathrm{~min}$ for the reaction to be completed and chromium absorption was measured at $540 \mathrm{~nm}$, using an ultraviolet-visible (UV-Vis) 
spectrophotometer (model U-2000, Hitachi, Tokyo, Japan). Total chromium concentrations were measured by Inductive Coupled Plasma-Mass Spectroscopy ICP-MS. The determination of divalent and total (divalent and trivalent) iron was performed by 1,10-phenanthroline method [23].

\section{Results and Discussion}

\subsection{Removal of Cr(VI) in Relation to the Dose of Fe(II)}

In these experiments the factor that affects the system is the concentration of ferrous iron that is available for reaction with hexavalent chromium after the mixing of the water with the reducing agent. Figure 2 shows that as the concentration of ferrous iron is increased, $\mathrm{Cr}(\mathrm{VI})$ percentage removal is also increased. The applied doses were $0.25,0.5,0.75$ and $1 \mathrm{mg} / \mathrm{L}$ at an initial chromium concentration of $50 \mu \mathrm{g} / \mathrm{L}$, corresponding to molar ratios of 4.8, 9.6, 14.4 and 19.2. For these molar ratios, $\mathrm{Cr}(\mathrm{VI})$ removal was in the order of $45 \%, 85 \%, 88 \%$ and $92 \%$ respectively. These results corresponded to residual $\mathrm{Cr}(\mathrm{VI})$ concentrations of about $24,8,6$ and $3 \mu \mathrm{g} / \mathrm{L}$ respectively.

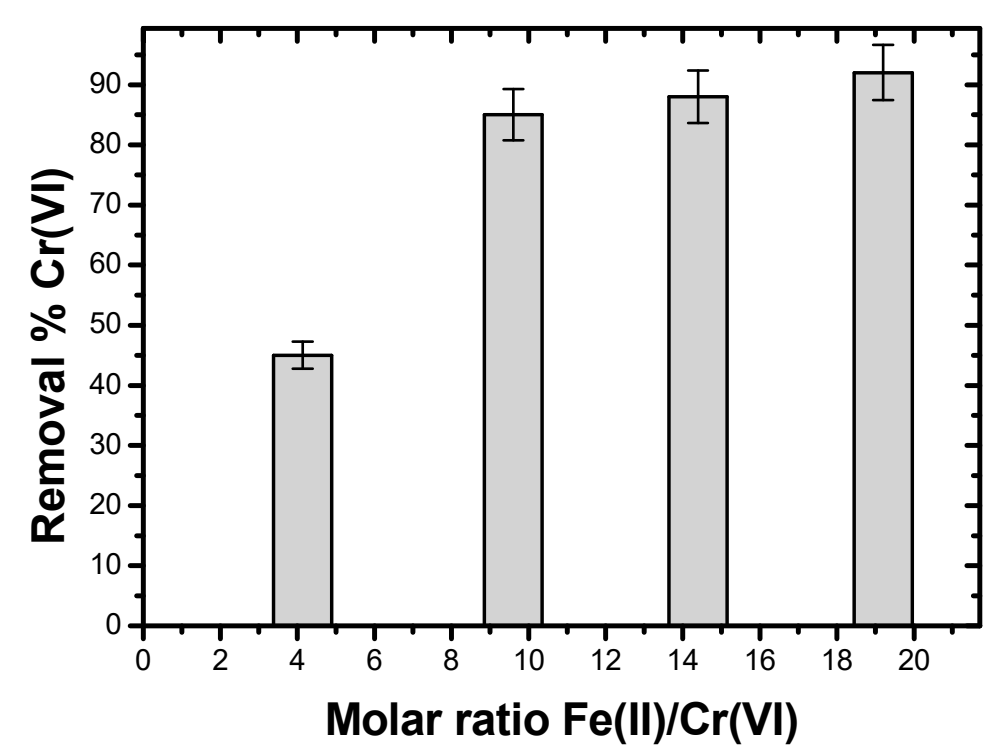

Figure 2. Removal of $\mathrm{Cr}(\mathrm{VI})$ as reated to the molar ratio of ferrous iron to hexavalent chromium. Experimental conditions: $\mathrm{Cr}(\mathrm{VI})$ initial concentration: $50 \mu \mathrm{g} / \mathrm{L}, \mathrm{Fe}(\mathrm{II})$ doses: 0.25, 0.5, 0.75, and $1 \mathrm{mg} / \mathrm{L}$, linear velocity: $8 \mathrm{~m} / \mathrm{h}$, value of $\mathrm{pH}: 7.3$.

Experiments were carried out at $\mathrm{pH}$ 7.3. At this $\mathrm{pH}$ value, total chromium was also very low (similar to $\mathrm{Cr}(\mathrm{VI})$ values). These results are in agreement with batch studies [15] and are quite improved from results obtained in continuous mode operation units, which instead of a pipe flocculation reactor, used a $\mathrm{Cr}(\mathrm{VI})$ reduction tank [14]. In the study of Qin et al., 2005 [14], it was shown that a molar ratio of $\mathrm{Fe}(\mathrm{II}) / \mathrm{Cr}(\mathrm{VI})$ of 9 to 56 was required to achieve a more than $90 \%$ total chromium removal for water containing 3-4 mg/L dissolved oxygen. In our experiments, a ratio of about 15 was needed for water containing dissolved oxygen of about $8 \mathrm{mg} / \mathrm{L}$. Given the fact that increased dissolved oxygen in water competes with $\mathrm{Cr}(\mathrm{VI})$ for $\mathrm{Fe}(\mathrm{II})$ oxidation, it is expected that $\mathrm{Fe}(\mathrm{II})$ oxidation takes place also by the dissolved oxygen, according to the kinetics of bivalent iron oxidation by oxygen [22]. Therefore, the results obtained provide evidence that the use of pipe flocculation reactors can be a more efficient reactor for reducing hexavalent to trivalent chromium than the use of $\mathrm{Cr}(\mathrm{VI})$ reduction tanks, since under fully oxic conditions, the unit achieved more than $90 \% \mathrm{Cr}(\mathrm{VI})$ removal by a molar ratio $\mathrm{Fe} / \mathrm{Cr}$ of about 15 , for a linear velocity of about $8 \mathrm{~m} / \mathrm{h}$.

To maintain the stable operation of the unit, the filters were backwashed once a day with clean drinking water and the sludge was collected and disposed. This helped to avoid replacing the sand very frequently. The sand is progressively coated with iron oxides, which as the literature studies 
suggest can enhance the rate of $\mathrm{Cr}(\mathrm{VI})$ reduction by $\mathrm{Fe}(\mathrm{II})$ and also oxidation of $\mathrm{Fe}(\mathrm{II})$ to $\mathrm{Fe}(\mathrm{III})$, when the dosing is over stoichiometric levels [20,22].

\subsection{Influence of Linear Velocity to the Removal of $\mathrm{Cr}(\mathrm{VI})$}

The effect of linear velocity was examined in this experimental section, by using [ $\mathrm{Fe}(\mathrm{II})] /[\mathrm{Cr}(\mathrm{VI})]$ molar proportion of 9.6. The applied flocculant dose was $0.5 \mathrm{mg} / \mathrm{L}$ at an initial chromium concentration of $50 \mu \mathrm{g} / \mathrm{L}$. With the increase of linear velocity, the time that is available in the tubular reactor for ferrous iron and hexavalent chromium to react is decreased. The linear velocity was adjusted to the values 4, 8, 12 and $15 \mathrm{~m} / \mathrm{h}$. A slight decrease in $\mathrm{Cr}(\mathrm{VI})$ removal with the increase of the linear velocity was noticed, as shown in Figure 2. For a linear velocity at $4 \mathrm{~m} / \mathrm{h}$ the chromium removal rate was $88 \%$, for linear velocity $8 \mathrm{~m} / \mathrm{h}$ the removal rate was $85 \%$, for linear velocity $12 \mathrm{~m} / \mathrm{h}$, the removal rate was at $86 \%$, for linear velocity at $15 \mathrm{~m} / \mathrm{h}$ the removal rate is at $83 \%$. These results are summarized in Figure 3 and show that there is a slight decrease in the removal of hexavalent chromium by increasing the linear velocity, especially at values higher than $15 \mathrm{~m} / \mathrm{h}$. This is mainly attributed to the fact that by increasing the linear velocity to higher values, the contact time of the water with the reagent is decreased and therefore, the time allowed for the $\mathrm{Fe}(\mathrm{II})$ reaction with $\mathrm{Cr}(\mathrm{VI})$ to take place will be decreased. However, the percentage removal of $83 \%$ at $15 \mathrm{~m} / \mathrm{L}$ is considered as a very satisfactory result, because this corresponds to residual $\mathrm{Cr}(\mathrm{VI})$ concentration of less than $10 \mu \mathrm{g} / \mathrm{L}$ and the daily water production accounts for about $1 \mathrm{~m}^{3} /$ day.

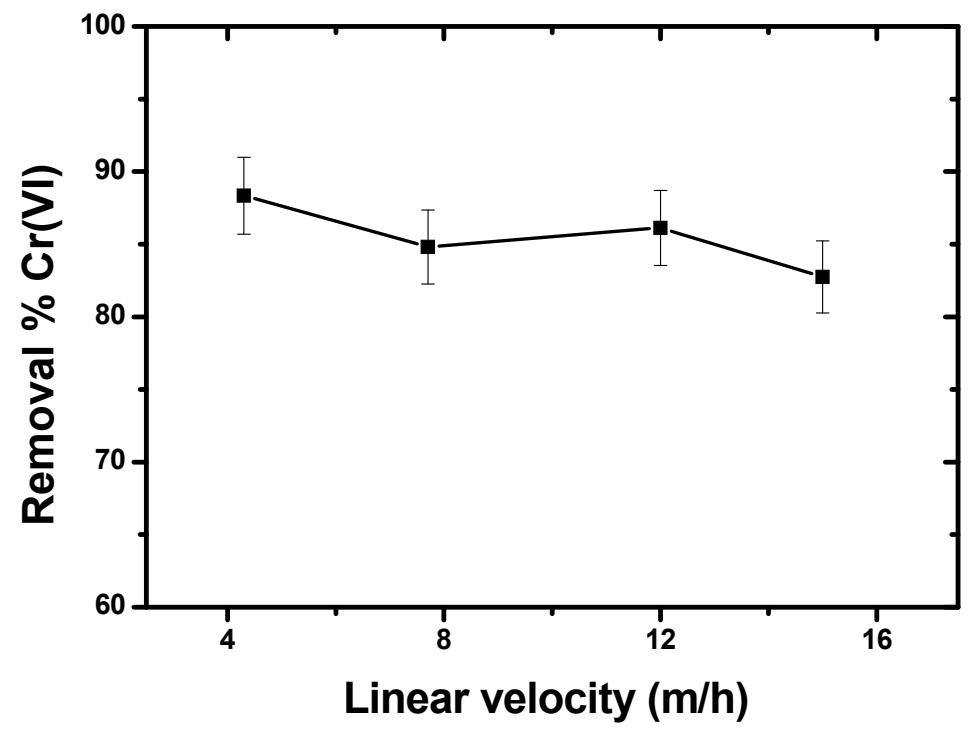

Figure 3. Removal of hexavalent chromium in relation to linear velocity. Experimental conditions: initial $\mathrm{Cr}(\mathrm{VI})$ concentration: $50 \mu \mathrm{g} / \mathrm{L}$, ferrous iron dose: $0.5 \mathrm{mg} / \mathrm{L}$, Linear velocity values: 4, 8, 12, $15 \mathrm{~m} / \mathrm{h}$, at $\mathrm{pH} 7.3$.

\subsection{Effect of the Initial Hexavalent Chromium Concentration}

In this part of experimental section, the examined parameter was the initial concentration of the hexavalent chromium. With the increase of the initial CR(VI) concentration, and by keeping Fe(II) concentration constant, the molar ratio $[\mathrm{Fe}(\mathrm{II})] /[\mathrm{Cr}(\mathrm{VI})]$ was decreased. In particular, for initial $\mathrm{Cr}(\mathrm{VI})$ concentrations of 50, 100, 200 and $400 \mu \mathrm{g} \mathrm{Cr}(\mathrm{VI}) / \mathrm{L}$, the molar ratio of $\mathrm{Fe} / \mathrm{Cr}$ decreases from 9.6, to 9.3, $4.65,2.32$ and 1.15 respectively. Figure 4 shows the corresponding results. With the gradual increase of the initial chromium concentration from $50 \mu \mathrm{g} / \mathrm{L}$ to $400 \mu \mathrm{g} / \mathrm{L}$, a decrease in chromium removal rate was noticed. In particular, for initial chromium (VI) concentration at $50 \mu \mathrm{g} / \mathrm{L}$ and $100 \mu \mathrm{g} / \mathrm{L}$ the removal rate was around $88 \%$ and $83 \%$, respectively. For the initial concentration at $200 \mu \mathrm{g} / \mathrm{L}$ the removal rate is at around $78 \%$ and for the initial chromium concentration at $400 \mu \mathrm{g} / \mathrm{L}$ the removal rate is at around $65 \%$. The residual chromium concentrations achieved were $6,17,44$ and $140 \mu \mathrm{g} / \mathrm{L}$ chromium, respectively. 


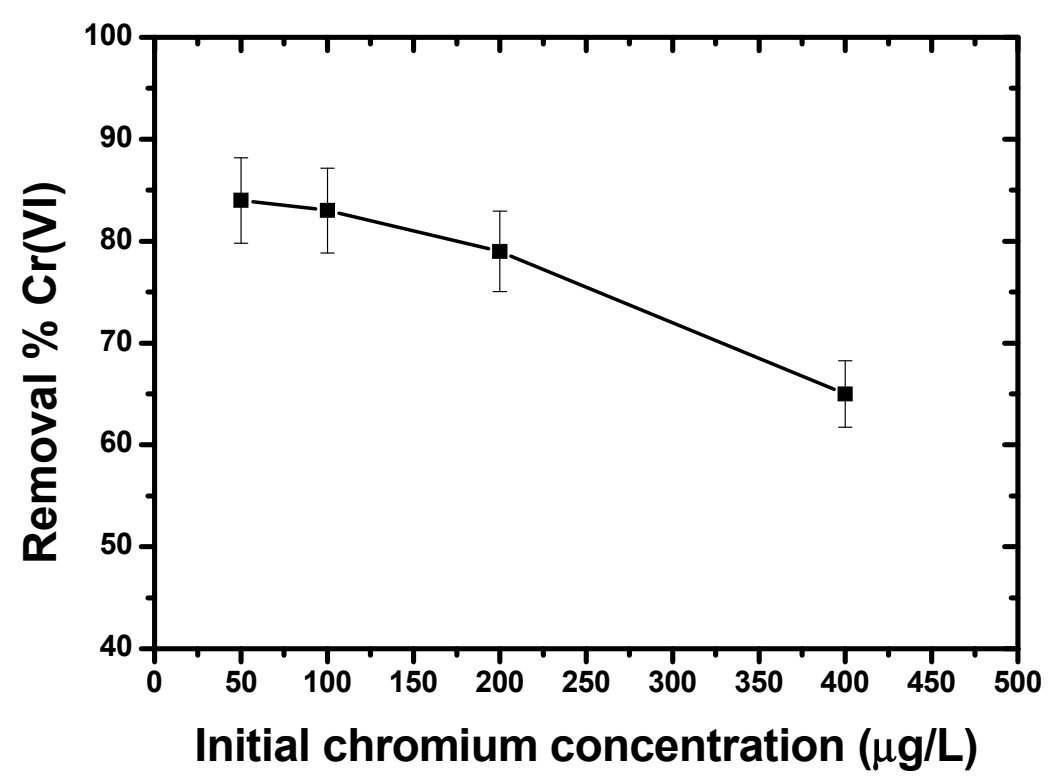

Figure 4. Influence of starting hexavalent chromium concentrations on $\mathrm{Cr}(\mathrm{VI})$ removal. Experimental conditions: initial $\mathrm{Cr}(\mathrm{VI})$ concentration 50, 100, 200, $400 \mu \mathrm{g} / \mathrm{L}$, flocculant dose $0.5 \mathrm{mg} / \mathrm{L}$, linear velocity $4 \mathrm{~m} / \mathrm{h}, \mathrm{pH}$ 7.3.

As the initial $\mathrm{Cr}(\mathrm{VI})$ concentration is increasing, the $\mathrm{Cr}(\mathrm{VI})$ removal rate is decreasing, apparently because the molar ratio $\mathrm{Fe}(\mathrm{II}) / \mathrm{Cr}(\mathrm{VI})$ becomes lower. Higher removal values at these ratios could not be achieved at the $\mathrm{pH}$ value at which the experiment was conducted, because of the competition of $\mathrm{Fe}(\mathrm{II})$ oxidation with the oxygen from water, since the kinetics of Fe(II) oxidation is mainly pH dependent and at $\mathrm{pH}$ values above $7, \mathrm{Fe}(\mathrm{II})$ oxidation by oxygen is very fast. This causes a competition between $\mathrm{Cr}(\mathrm{VI})$ and $\mathrm{O}_{2}$ to oxidize $\mathrm{Fe}(\mathrm{II})$. In particular, Buerge and Hug, (1997) [24] have reported that $\mathrm{Cr}(\mathrm{VI})$ oxidizes $\mathrm{Fe}(\mathrm{II})$ faster than $\mathrm{O}_{2}$ for $[\mathrm{Cr}(\mathrm{VI})]=\left[\mathrm{O}_{2}\right]$ by a factor of about $3 \times 10^{4}$ at $\mathrm{pH} 4,6 \times 10^{3}$ at $\mathrm{pH} 6$ and $1 \times 10^{3}$ at $\mathrm{pH} 8$. This highlights that by increasing the $\mathrm{pH}$ of water, increased $\mathrm{Fe}(\mathrm{II})$ concentration is need to oxidized the same concentration of $\mathrm{Cr}(\mathrm{VI})$. For higher initial $\mathrm{Cr}(\mathrm{VI})$ concentrations, the final concentrations were much higher than the current and proposed limits for $\mathrm{Cr}(\mathrm{VI})$ in water.

The interesting finding of this experiment, however, is that although the percentage of $\mathrm{Cr}(\mathrm{VI})$ removal is decreasing and the residual concentrations of $\mathrm{Cr}(\mathrm{VI})$ are increasing, the amount of $\mathrm{Cr}(\mathrm{VI})$ removed in $\mu \mathrm{g} / \mathrm{L}$ is increasing. For example, when the initial concentration was 50 , the amount of $\mathrm{Cr}(\mathrm{VI})$ removed was about $45 \mu \mathrm{g} / \mathrm{L}$, whereas for initial concentration of $\mathrm{Cr}(\mathrm{VI})$ of $400 \mu \mathrm{g} / \mathrm{L}$, the amount removed was $256 \mu \mathrm{g} / \mathrm{L}$. Both results were obtained by the same dosing quantity of $\mathrm{Fe}(\mathrm{II})$, namely $0.5 \mathrm{mg} / \mathrm{L}$. This might indicate an autocatalytic effect of $\mathrm{Cr}(\mathrm{VI})$ concentration on $\mathrm{Cr}(\mathrm{VI})$ reduction by $\mathrm{Fe}(\mathrm{II})$, i.e., by increasing the kinetics of $\mathrm{Fe}(\mathrm{II})$ oxidation by $\mathrm{Cr}(\mathrm{VI})$. This might be critical in the removal of high concentrations of $\mathrm{Cr}(\mathrm{VI})$ and provides evidence that multiple additions of $\mathrm{Fe}(\mathrm{II})$ in the water might be more efficient that dosing all the Fe(II) quantity at once. These results are in agreement with a study by Schlautman and Han (2001) [25], who examined Cr(VI) reduction by dissolved ferrous in under-stoichiometric conditions, i.e., representing a deficient amount of $\mathrm{Fe}(\mathrm{II})$.

In addition, the idea of multiple dosing of the reagent could also contribute to the reduction of the produced sludge. Indeed, this technology produces some sludge, which has to be handled. There are several ways of handling sludge from water treatment processes, such as dewatering, stabilizing and disposal to landfills, but the most important aspect is to reduce the amount of sludge produced, which can be potentially achieved by the multiple dosing suggestion in a unit operation such as that proposed in the present study.

The chromium removal results from all the experiments in this study were in agreement with the results from previous studies, examining $\mathrm{Cr}(\mathrm{VI})$ removal in batch mode operation [15]. Mitrakas et al. (2011) [15] found that for $\mathrm{pH} 7.5-8$ and for ratio [Fe(II)]/[Cr(VI)] equal to 5, the chromium removal is 
up to 40-60\%, a result that has also been achieved in this study. Mitrakas et al., 2011 [15], claimed that the optimal ratio [Fe (II)]/[Cr (VI)] for $\mathrm{Cr}(\mathrm{VI})$ removal equal or greater than $90 \%$ is $15-20$, at $\mathrm{pH} 7.5$ and $25^{\circ} \mathrm{C}$. Our experiments are also in agreement with this claim to achieve chromium removal rate more than $90 \%$ and as previously discussed with other similar studies [14].

A previous study by Stylianou et al., 2017 [20], examined the removal of $\mathrm{Cr}$ (VI) by Fe(II) using pipe flocculation followed by ultrafiltration, with part of the sludge to be recirculated into the pipe reactors. This unit was similar to that examined in present study, with the difference that in the present study, the sludge was not recirculated. In this study it was shown that $\mathrm{Cr}(\mathrm{VI})$ concentrations in the order of $300 \mu \mathrm{g} / \mathrm{L}$ could be removed to lower than $10 \mu \mathrm{g} / \mathrm{L}$ by a dosage of $1 \mathrm{mg} / \mathrm{L} \mathrm{Fe}(\mathrm{II})$ at neutral pH values. This corresponds to a molar ratio $\mathrm{Fe}(\mathrm{II}) / \mathrm{Cr}(\mathrm{VI})$ somewhat higher than 3, which is much below the respective values obtained in the present study and the available publications for standard $\mathrm{Cr}(\mathrm{VI})$ removal techniques by Fe(II). Therefore, another aim of this study was to prove indirectly that the recirculation of the sludge in units with plug flow reactors could act in a catalytic way and enhance the kinetics of the $\mathrm{Fe}(\mathrm{II})$ reaction with $\mathrm{Cr}(\mathrm{VI})$, thus reducing the respective competition by the reaction of $\mathrm{Fe}(\mathrm{II})$ with oxygen and finally reducing the amount of Ferrous sulphate needed for the optimized $\mathrm{Cr}(\mathrm{VI})$ removal from water. In addition, this process contributes to the reduction of the chromium-containing sludge produced. This is very important, especially for treatment units designed to operate at the household level, because the sludge handling for small units is a matter of concern, since it is expected to increase the operational costs to a disproportionate degree. Moreover, this is particularly significant, because this method has the overall disadvantage of the difficulty in capturing the end moment of $\mathrm{Cr}(\mathrm{VI})$ reduction to $\mathrm{Cr}(\mathrm{III})$, thus in conventional treatment (i.e., all reagent dosing at once and once through filtration without any recirculation) the end point cannot be captured and more reagent than needed is usually dosed. In these cases, the process can be monitored closer resulting in less reagent requirements, thus making it more possible to dose closer to the end point of reduction reactions.

\section{Conclusions}

The results of the present study showed that the examined experimental set up, compromising plug flow reactors followed by sand filtration, could achieve $\mathrm{Cr}(\mathrm{VI})$ removal rates of more than $90 \%$. These results are satisfying because the possible future limit for $\mathrm{Cr}(\mathrm{VI})$ in drinking water at 25 or $10 \mu \mathrm{g} / \mathrm{L}$ was achieved, even under $\mathrm{pH}$ and dissolved oxygen conditions that favor the competition for Fe(II) oxidation between oxygen and $\mathrm{Cr}(\mathrm{VI})$. The removal of hexavalent chromium from initial concentrations of $50 \mu \mathrm{g} / \mathrm{L}$ was efficient with a coagulant dose of $1 \mathrm{mg} / \mathrm{L}$ and a linear velocity of $8 \mathrm{~m} / \mathrm{h}$ at $\mathrm{pH}$ 7.3. The further advantage of this study was that the treatment could result in the production of about $1 \mathrm{~m}^{3}$ /day drinking water, which could satisfy the needs of a family in rural areas who are exposed to $\mathrm{Cr}(\mathrm{VI})$-contaminated groundwater and do not have access to community piped drinking water. Increasing the linear velocity, thus producing more drinking water per day, showed a slight decrease in chromium removal rate, but even at a rate of $15 \mathrm{~m} / \mathrm{h}$, the residual concentration of $\mathrm{Cr}(\mathrm{VI})$ was lower than $10 \mu \mathrm{g} / \mathrm{L}$ from initial concentration of $50 \mu \mathrm{g} / \mathrm{L}$. In experiments with increasing concentrations of $\mathrm{Cr}(\mathrm{VI})$, thus applying under-stoichiometric $\mathrm{Fe} / \mathrm{Cr}$ molar ratio values, the mass of $\mathrm{Cr}(\mathrm{VI})$ reduced per mass of $\mathrm{Fe}(\mathrm{II})$ dose increased by decreasing the $\mathrm{Fe} / \mathrm{Cr}$ molar ratio, although the percentage $\mathrm{Cr}(\mathrm{V})$ removal rate decreased. This might indicate, that when treating waters with relatively high concentrations of $\mathrm{Cr}(\mathrm{VI})$, multiple dosages of $\mathrm{Fe}(\mathrm{II})$ might be more efficient than dosing the entire quantity at once, thus cutting the amount of reducing reagent dosed and correspondingly the amount of sludge produced.

Author Contributions: I.A.K. and A.I.Z. conceived, designed and supervised the experiments and the revision of the draft paper. M.X. conducted the experiments and wrote the draft paper. All authors have read and agreed to the published version of the manuscript.

Funding: This research received no external funding.

Conflicts of Interest: The authors declare no conflict of interest. 


\section{References}

1. Kaprara, E.; Kazakis, N.; Simeonidis, K.; Coles, S.; Zouboulis, A.; Samaras, P.; Mitrakas, M. Occurrence of $\mathrm{Cr}(\mathrm{VI})$ in Drinking Water of Greece and Relation to the Geological Background. J. Hazard. Mater. 2015, 281, 2-11. [CrossRef] [PubMed]

2. Kazakis, N.; Kantiranis, N.; Voudouris, K.; Mitrakas, M.; Kaprara, E.; Pavlou, A. Geogenic Cr Oxidation on the Surface of Mafic Minerals and the Hydrogeological Conditions Influencing Hexavalent Chromium Concentrations in Groundwater. Sci. Total Environ. 2015, 514, 224-238. [CrossRef] [PubMed]

3. Mohan, D.; Pittmann, C.U., Jr. Activated Carbons and Low Cost Adsorbents for Remedia-Tion of Tri- and Hexavalent Chromium from Water. J. Hazard. Mater. 2006, 137, 762-811. [CrossRef] [PubMed]

4. Katsoyiannis, I.A.; Gachet, C.; von Gunten, U. Fate of Cr (III) during Ozonation of Secondary Municipal Wastewater Effluent. Ozone Sci. Eng. 2018, 40, 441-447. [CrossRef]

5. Ball, J.; Izbicki, J. Occurrence of Hexavalent Chromium in Ground Water in the Western Mojave Desert, California. Appl. Geochem. 2004, 19, 1123-1135. [CrossRef]

6. Sharma, S.; Petrusevski, B.; Amy, G. Chromium Removal From Water: A Review. J. Water Supply Res. Technol.-AQUA 2008, 57, 541-553. [CrossRef]

7. Office of Dietary Supplements. Dietary Supplement Fact Sheet: Chromium. Available online: https:/ods.od.nih.gov/factsheets/Chromium-HealthProfessional/ (accessed on 16 September 2019).

8. Costa, M. Potential Hazards of Hexavalent Chromate in Our Drinking Water. Toxicol. Appl. Pharmacol. 2003, 188, 1-5. [CrossRef]

9. Linos, A.; Petralias, A.; Christophi, C.; Christoforidou, E.; Kouroutou, P.; Stoltidis, M.; Veloudaki, A.; Tzala, E.; Makris, K.; Karagas, M. Oral Ingestion of Hexavalent Chromium Through Drinking Water and Cancer Mortality in an Industrial Area of Greece-An Ecological Study. Environ. Health 2011, 10, 50. [CrossRef] [PubMed]

10. Chromium-6 Drinking Water MCL | California State Water Quality Control Board. Available online: https://www.waterboards.ca.gov/drinking_water/certlic/drinkingwater/Chromium6.html (accessed on 9 December 2019).

11. European Commission. Proposal for a Directive of the European Parliament and of the Council on the Quality of Water Intended for Human Consumption. 2018. Available online: https://ec.europa.eu/environment/ water/water-drink/pdf/revised_drinking_water_directive.pdf (accessed on 5 December 2019).

12. Yoshitake, H.; Yokoi, T.; Tatsumi, T. Adsorption of Chromate and Arsenate by Amino-Functionalized MCM-41 and SBA-1. Chem. Mater. 2002, 14, 4603-4610. [CrossRef]

13. González, P.S.; Ambrosio, L.F.; Paisio, C.E.; Talano, M.A.; Medina, M.I.; Agostini, E. Chromium (VI) remediation by a native strain: Effect of environmental conditions and removal mechanisms involved. Environ. Sci. Pollut. Res. 2014, 23, 13551-13559. [CrossRef] [PubMed]

14. Qin, G.; Mcguire, M.J.; Blute, N.K.; Seidel, C.; Fong, L. Hexavalent Chromium Removal by Reduction with Ferrous Sulfate, Coagulation, and Filtration: A Pilot-Scale Study. Environ. Sci. Technol. 2005, 39, 6321-6329. [CrossRef] [PubMed]

15. Mitrakas, M.; Pantazatou, A.; Tzimou-Tsitouridou, R.; Sikalidis, C. Influence of Ph and Temperature on Cr(VI) Removal from a Natural Water Using Fe(II): A Pilot and Full Scale Case Study. Desalin. Water Treat. 2011, 33, 77-85. [CrossRef]

16. Papadopoulos, G.; Asimakidou, T.; Karfaridis, D.; Kellartzis, I.; Vourlias, G.; Mitrakas, M.; Simeonidis, K. An Optimized Cr(VI)-Removal System Using Sn-based Reducing Adsorbents. Water 2019, 11, 2477. [CrossRef]

17. Abdullah, N.; Yusof, N.; Abu Shah, M.; Wan Ikhsan, S.; Ng, Z.; Maji, S.; Lau, W.; Jaafar, J.; Ismail, A.; Ariga, K. Hydrous Ferric Oxide Nanoparticles Hosted Porous Polyethersulfone Adsorptive Membrane: Chromium (VI) Adsorptive Studies and Its Applicability for Water/Wastewater Treatment. Environ. Sci. Pollut. Res. 2019, 26, 20386-20399. [CrossRef] [PubMed]

18. Agrawal, A.; Kumar, V.; Pandey, B. Remediation Options for the Treatment of Electroplating and Leather Tanning Effluent Containing Chromium-A Review. Miner. Process. Extr. Metall. Rev. 2006, 27, 99-130. [CrossRef]

19. Gröhlich, A.; Langer, M.; Mitrakas, M.; Zouboulis, A.; Katsoyiannis, I.; Ernst, M. Effect of Organic Matter on $\mathrm{Cr}(\mathrm{VI})$ Removal From Groundwaters By Fe(II) Reductive Precipitation for Groundwater Treatment. Water 2017, 9, 389. [CrossRef] 
20. Stylianou, S.; Simeonidis, K.; Mitrakas, M.; Zouboulis, A.; Ernst, M.; Katsoyiannis, I. Reductive Precipitation and Removal of $\mathrm{Cr}(\mathrm{VI})$ from Groundwaters by pipe Flocculation-Microfiltration. Environ. Sci. Pollut. Res. 2017, 25, 12256-12262. [CrossRef] [PubMed]

21. Sustainable Development Goals. Sustainable Development Knowledge Platform. Available online: https: //sustainabledevelopment.un.org/?menu=1300 (accessed on 9 December 2019).

22. Stumm, W.; Morgan, J. Aquatic Chemistry, 3rd ed.; John Wiley \& Sons: New York, NY, USA, 1996.

23. Rice, E.; Baird, R.; Eaton, A.; Clesceri, L. Standard Methods for Examination of Water and Wastewater 2012; American Public Health Association: Washington, DC, USA, 2012.

24. Buerge, I.; Hug, S. Kinetics and pH Dependence of Chromium(VI) Reduction by Iron(II). Environ. Sci. Technol. 1997, 31, 1426-1432. [CrossRef]

25. Schlautman, M.; Han, I. Effects of Ph and Dissolved Oxygen on the Reduction of Hexavalent Chromium by Dissolved Ferrous Iron in Poorly Buffered Aqueous Systems. Water Res. 2001, 35, 1534-1546. [CrossRef]

(C) 2020 by the authors. Licensee MDPI, Basel, Switzerland. This article is an open access article distributed under the terms and conditions of the Creative Commons Attribution (CC BY) license (http://creativecommons.org/licenses/by/4.0/). 